\title{
PAPERS
}

\section{Predictive value of endoscopic ultrasonography for regression of gastric low grade and high grade MALT lymphomas after eradication of Helicobacter pylori}

S Nakamura, T Matsumoto, H Suekane, M Takeshita, K Hizawa, M Kawasaki, T Yao, M Tsuneyoshi, M Iida, M Fujishima

\begin{abstract}
Background-While a close association between gastric mucosa associated lymphoid tissue (MALT) lymphoma and Helicobacter pylori infection has been established, there are still cases which do not respond to $H$ pylori eradication.

Aims-To investigate the clinicopathological factors which may help predict the therapeutic efficacy of $\boldsymbol{H}$ pylori eradication in gastric MALT lymphoma.

Patients-Forty one patients with gastric MALT lymphoma, including low and high grade lesions.

Methods-After endosonographic staging was determined, $\boldsymbol{H}$ pylori was eradicated in all patients, and the subsequent gastric pathological course was then investigated. Results-Complete regression of MALT lymphoma was observed in $29(71 \%)$ patients, partial regression in five $(12 \%)$, and no regression in seven $(17 \%)$. Twenty six (93\%) of 28 MALT lymphomas restricted to the mucosa but only three $(23 \%)$ of 13 lymphomas which invaded the deep portion of the submucosa or beyond completely regressed. Kaplan-Meier analysis for the probability of complete regression of MALT lymphoma revealed a significant difference between tumours restricted to the mucosa and those invading the submucosa deeply or beyond $(p<0.05)$. Neither the presence of a high grade component, perigastric lymphadenopathy, nor clinical staging prior to eradication correlated with the probability of lymphoma regression.
\end{abstract}

Conclusions-Assessment of deep submucosal invasion by endosonography is valuable for predicting the efficacy of $H$ pylori eradication in gastric MALT lymphoma. (Gut 2001;48:454-460)

Keywords: gastric lymphoma; mucosa associated lymphoid tissue; Helicobacter pylori; endoscopic ultrasonography

The stomach is one of the most common sites of extranodal malignant lymphoma, and primary gastric lymphoma comprises $1-7 \%$ of all gastric malignant neoplasms. ${ }^{12}$ These lymphomas are usually of B cell origin and the majority of such cases are considered to have arisen from the mucosa associated lymphoid tissue (MALT) associated with Helicobacter pylori infection. $^{3-5}$ Recent reports have shown a certain proportion of gastric low grade MALT lymphoma to regress after eradication of $H$ pylori. ${ }^{6-11}$ However, little is known with regard to which individuals benefit from this treatment. Sackmann and colleagues ${ }^{12}$ recently described the usefulness of endoscopic ultrasonography (EUS) in predicting the response of gastric MALT lymphoma to $H$ pylori eradication based on a prospective study with a relatively small number of patients.

In our study, we prospectively evaluated the initial response to $H$ pylori eradication in 53 patients with gastric lymphoproliferative diseases and analysed in detail their clinicopathological factors to verify the value of EUS for the management of gastric MALT lymphoma in relation to $H$ pylori eradication.

\section{Patients and methods}

SUBJECTS AND PROTOCOL

This study was conducted in 53 patients suspected of having gastric MALT lymphoma who were treated from 1994 to 1998. A histological score for MALT lymphoma ${ }^{6}$ of 3 or greater in gastric biopsy specimens and positive $H$ pylori infection, as determined by culture, serology, histology, and immunohistochemistry, were the criteria for inclusion. Patients consisted of 21 men and 32 women, and mean age at entry was 60 years (range $36-81$ ).

After determining the clinical stage and histological score for MALT lymphoma, $H$ pylori was eradicated by a proton pump inhibitor (omeprazole, lansoprazole, or rabeprazole) together with a combination of antibiotics (clarithromycin, amoxicillin, and/or metronidazole). Follow up examinations were performed by endoscopy together with biopsies every four to eight weeks after the end of eradication (follow up time 1-52 months; median

Abbreviations used in this paper: MALT, mucosa associated lymphoid tissue; EUS, endoscopic ultrasonography; RLH, reactive lymphoid hyperplasia. 
12.4 months). Complete regression of the lymphomatous lesion was defined as a histological score for MALT lymphoma of 2 or less on post-treatment biopsy specimens at anytime during the follow up period, as described below. The lesion was considered to represent partial regression when it obviously regressed endoscopically but the post-treatment biopsy samples showed a histological score of 3 or greater. Patients exhibiting no endoscopic or histological response six weeks after the end of eradication were considered to have failed to respond to $H$ pylori eradication. Such patients were subjected to alternative treatment strategies. Informed consent was obtained from each patient with regard to the aims and protocol of the study.

ASSESSMENT OF HISTOLOGY

Histological specimens obtained by endoscopic biopsy and/or endoscopic mucosal resection $^{13}$ were independently evaluated by two pathologists (SN and M Takeshita). If the histological diagnosis differed between the two pathologists, they discussed each case until a consensus was obtained. The specimens were graded from 0 to 5 according to the histological scoring system for the diagnosis of MALT lymphoma proposed by Wotherspoon and colleagues. ${ }^{6}$ A diagnosis of MALT lymphoma was made when: (1) the histological score of any one specimen was 5 (indicating the presence of dense diffuse infiltrate of centrocyte-like cells in the lamina propria with prominent lymphoepithelial lesions); or (2) two or more specimens had a score of 4 (suspicious lymphoid infiltrate in the lamina propria, probably lymphoma) while a polymerase chain reaction proved monoclonal rearrangement of the immunoglobulin heavy chain gene. ${ }^{6914}$ All other patients were diagnosed as having reactive lymphoid hyperplasia (RLH) in the present investigation. A post-treatment score of 2 or less was regarded as complete regression. ${ }^{8}$

The pressence of a high grade component was also carefully evaluated ${ }^{14-16}$; a high grade component was considered to be present when compact clusters or sheets of large atypical lymphoid cells (centroblast-like or lymphoblast-like cells) were observed in at least $1 \%$ or more of the neoplastic lymphoid population, as defined by de Jong and colleagues. ${ }^{16}$ Immunophenotyping (B cell/ $\mathrm{T}$ cell) and immunoglobulin light chain restriction were assessed by monoclonal antibodies, including kappa, lambda, CD20 (L26), CD45RO (UCHL1, OPD4), and a polyclonal antibody CD3 (Dako, Glostrup, Denmark). ${ }^{2} H$ pylori density in both the affected (5-27 biopsied samples per patient, mean 11.0) and unaffected (two samples - one from the corpus and one from the antrum-per patient) areas within the stomach was scored from 0 to 3 according to the updated Sydney system, ${ }^{17}$ after all specimens were immunostained with polyclonal rabbit anti- $H$ pylori antibody B471 (Dako). ${ }^{514}$ The highest grade among multiple samples was chosen for individual $H$ pylori density.
STAGING PROCEDURES

The findings on a physical examination (including Waldeyer's ring and nasopharynx), routine laboratory tests, chest radiographs, abdominal ultrasound, computerised tomography of the abdomen and pelvis, and bone marrow aspiration were assessed in all patients prior to $H$ pylori eradication. Gallium scintigraphy (34 patients) and computerised tomography of the chest (22 patients) were performed when an advanced stage was suspected. The clinical stage of lymphoma was determined according to Musshoff's modification of the Ann Arbor staging system. ${ }^{18} 19$

The endoscopic appearance of the lymphoma was classified as either superficial spreading type, mass forming type, diffuse infiltrating type, or unclassified. ${ }^{20}$ EUS was performed by one of three echoendoscopists (HS, KH, or MK) who were blinded to the histological findings. The affected area was scanned by radial sector transducers (GFUM3 or GF-UM20, Olympus, Tokyo, Japan) at a frequency of $7.5 \mathrm{MHz}$ or $12 \mathrm{MHz}$. Depth of tumour invasion in the gastric wall was classified as mucosa when the lesion was localised within the first and second layers with preservation of the third layer (this pattern may include tumours restricted to the superficial portion of the submucosa) (fig 1A), as submucosa with a hypoechoic area in the third layer (fig 1B), as muscular layer with involvement of the fourth layer (fig 1C), or beyond (fig 1D).$^{20-22}$ Perigastric lymphadenopathy (possible lymph node involvement) was considered to be present when hypoechoic enlarged nodes measuring over $10 \mathrm{~mm}$ in diameter could be detected by EUS (fig 2A). Furthermore, the EUS staging system reported by the German MALT Lymphoma Study Group $\left(\mathrm{EI}_{1}, \mathrm{EI}_{2}\right.$, or EII $)^{712}$ was also incorporated into our findings; this staging system was identical to the modified Ann Arbor system regarding depth of tumour invasion. ${ }^{23}$

\section{STATISTICAL ANALYSES}

The post-treatment probability of complete regression of MALT lymphoma was calculated by the Kaplan-Meier method and compared between the two groups using the log rank test. Other statistical differences were evaluated using Fisher's exact probability test, the $\chi^{2}$ test, or the Mann-Whitney U test. A p value less than 0.05 for each test was regarded as statistically significant.

\section{Results}

Based on the detailed histological evaluations of the pretreatment biopsied and/or endoscopically resected specimens, 41 patients were finally diagnosed as having MALT lymphoma (37 cases with a score of 5 , four cases with a score of 4 and showing a monoclonal rearrangement of the immunoglobulin heavy chain gene), and 12 as RLH of the stomach. In 48 of the 53 patients, complete concordance was achieved between the two pathologists for the histological diagnosis. In the other five patients further discussion was necessary to obtain a consensus. In 41 MALT lymphoma cases, 31 
Table 1 Comparison of the clinicopathological findings between patients

\begin{tabular}{|c|c|c|c|}
\hline Characteristics & $\begin{array}{l}\text { MALT lymphoma } \\
(n=41)(\%)\end{array}$ & $\begin{array}{l}R L H \\
(n=12)(\%)\end{array}$ & $p$ Value \\
\hline \multicolumn{4}{|l|}{ Sex } \\
\hline Male & $17(41)$ & $4(33)$ & \multirow[t]{2}{*}{$\mathrm{NS}^{\star}$} \\
\hline Female & $24(59)$ & $8(67)$ & \\
\hline \multicolumn{4}{|l|}{ Age $(y)$} \\
\hline Mean (SD) & $61(9)$ & $56(15)$ & \multirow[t]{2}{*}{ NSt } \\
\hline Range & [43-81] & [36-78] & \\
\hline \multicolumn{4}{|l|}{ Dominant site of lesion } \\
\hline Fundus & $13(32)$ & $1(8)$ & \multirow{3}{*}{ NS $\ddagger$} \\
\hline Corpus & $21(51)$ & $9(75)$ & \\
\hline Antrum & $7(17)$ & $2(17)$ & \\
\hline H pylori density (mean (SD)) & $2.1(0.9)$ & $2.6(0.5)$ & NS† \\
\hline \multicolumn{4}{|l|}{ Follow up period (months) } \\
\hline Mean (SD) & $17(15)$ & $13(11)$ & \multirow{2}{*}{$\mathrm{NS}+$} \\
\hline Range & {$[1-52]$} & [3-37] & \\
\hline \multicolumn{4}{|l|}{ Response of $H$ pylori eradication } \\
\hline Complete regression & $29(71)$ & $12(100)$ & \multirow[t]{2}{*}{$0.030^{\star}$} \\
\hline Partial or no regression & $12(29)$ & $0(0)$ & \\
\hline
\end{tabular}

MALT, mucosa associated lymphoid tissue; RLH, reactive lymphoid hyperplasia.

^Fisher's exact probability test; $†$ Mann-Whitney U test; $\ddagger \chi^{2}$ test.

१Updated Sydney system. lymphoma group, but these differences were not statistically significant. Endoscopically, 32 cases of MALT lymphoma were classified as superficial spreading type, seven as mass forming type, and two as diffuse infiltrating type; all RLH cases were considered superficial spreading type lesions.

Complete eradication of $H$ pylori was obtained in all 53 patients; in one patient with MALT lymphoma, reinfection by $H$ pylori was noted three months after the initial successful eradication with partial regression of the lymphoma, and a second treatment with rabeprazole $(20 \mathrm{mg} /$ day $)$ plus metronidazole (750 mg/day), clarithromycin (600 mg/day), and amoxicillin (2000 mg/day) was necessary to cure the reinfection. During follow up after eradication of $H$ pylori, complete regression was observed in 29 of 41 MALT lymphoma patients $(71 \%)$, partial regression in five $(12 \%)$, and no regression or progression in seven (17\%), while all RLH patients had complete regression $(\mathrm{p}<0.05)$ (table 1$)$. The follow up period in the 29 MALT lymphoma patients with complete regression ranged from 5 to 52 months (median 20.5). The time from the end of eradication until initial confirmation of complete regression ranged from 1 to 18 months (median 2.3). In these 29 patients, no relapse was observed during the follow up period after reaching complete regression, ranging from 3 to 51 months (median 11.3). Alternative therapies were given to seven
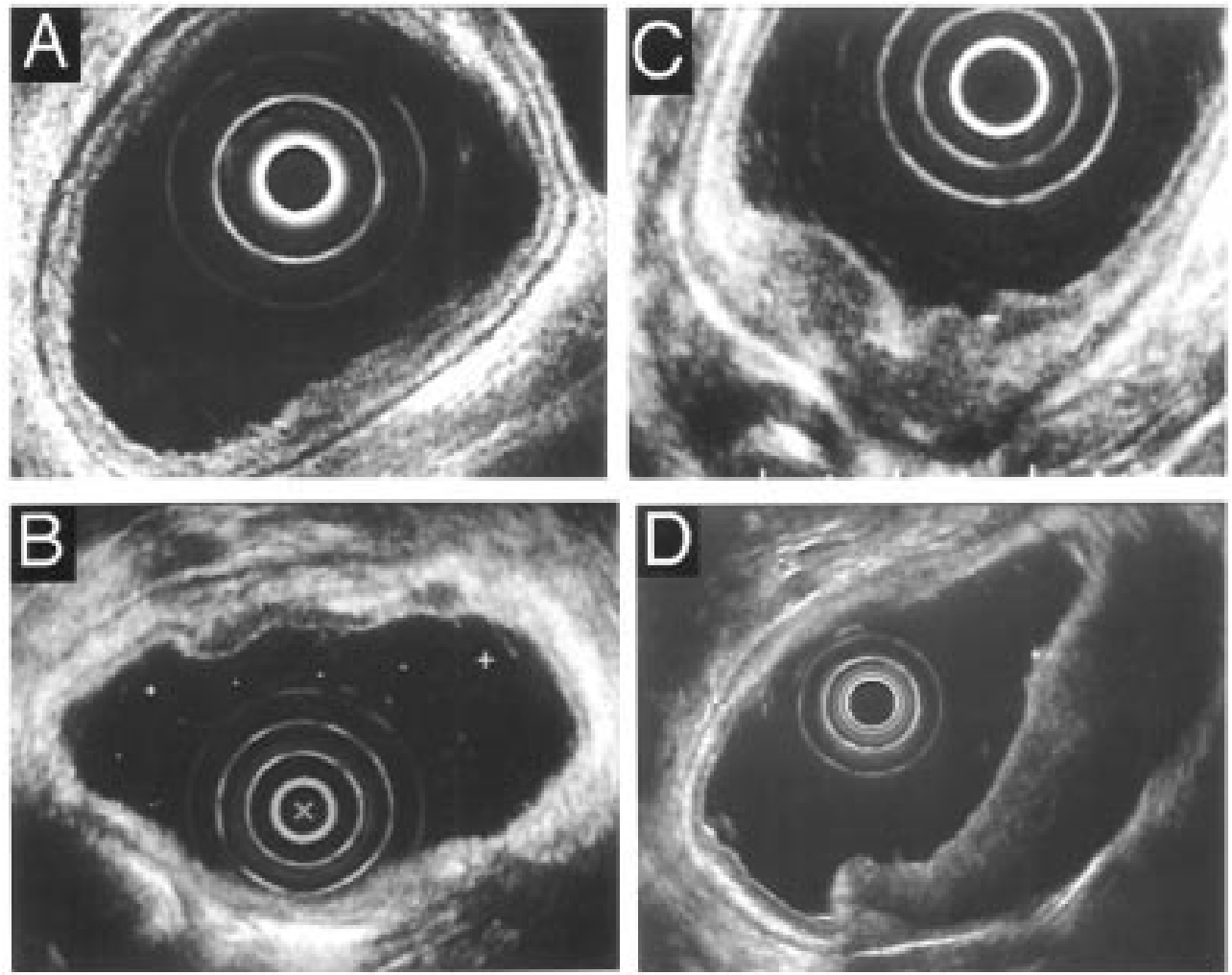

Figure 1 Pretreatment endoscopic ultrasonographic images of gastric mucosa associated lymphoid tissue (MALT) lymphomas. (A) A 43 year old man showed low grade MALT lymphoma, without any evidence of a high grade component, restricted to the mucosa with no significant submucosal invasion. (B) $A$ 68 year old woman showed a high grade MALT lymphoma with a low grade component invading the deep portion of the submucosa. (C) $A$ 62 year old man showed high grade MALT lymphoma with a low grade component invading the muscularis propria. (D) $A 72$ year old male patient showed high grade MALT lymphoma with a low grade component involving the serosa. 

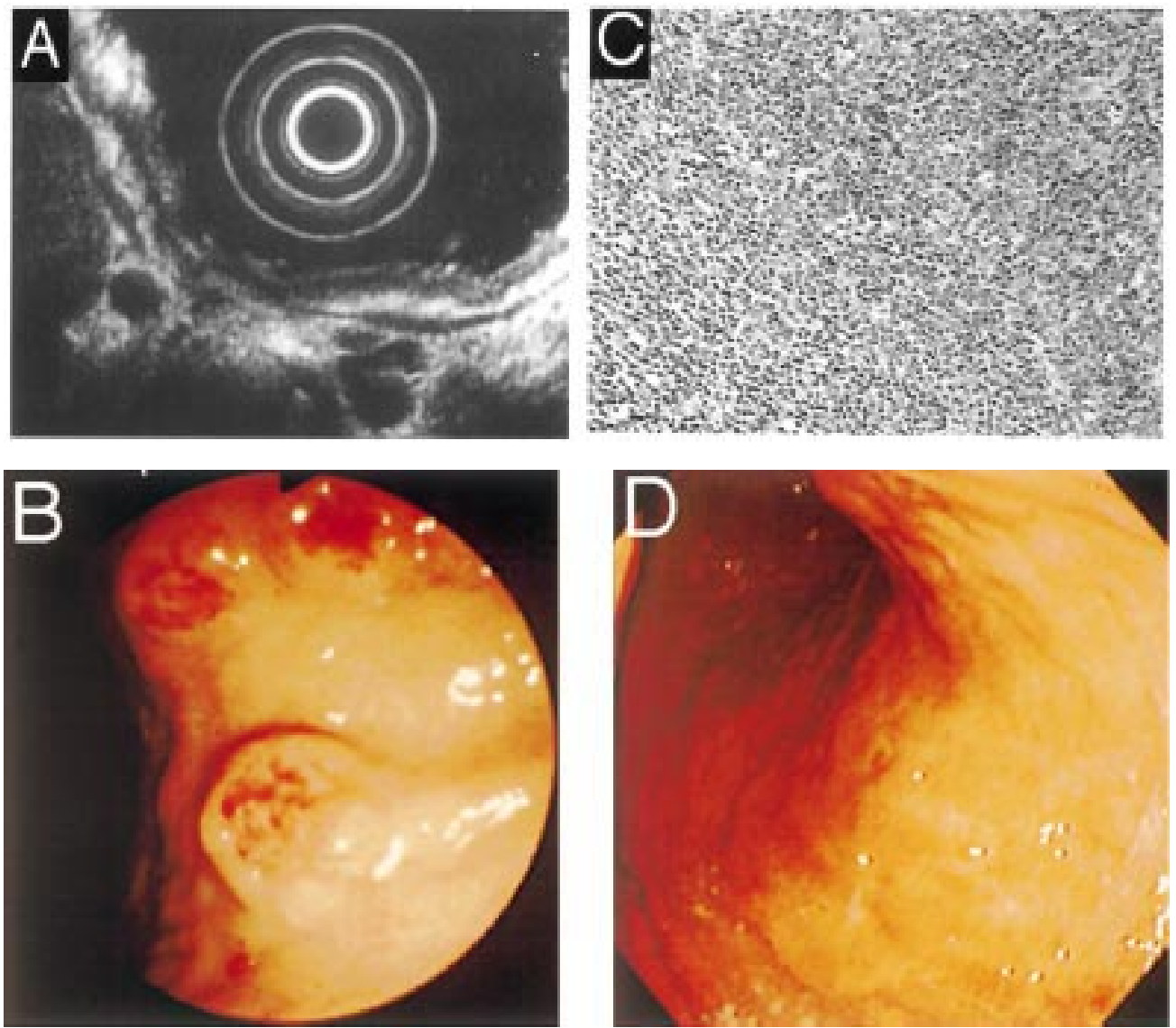

Figure 2 A 68 year old female case of high grade mucosa associated lymphoid tissue (MALT) lymphoma with a low grade component in stage EII, deeply invading the submucosa, which regressed after eradication therapy. (A) Pretreatment endoscopic ultrasonography demonstrates enlargement of many perigastric lymph nodes. (B) Pretreatment endoscopy reveals multiple polypoid lesions with a central erythematous depression in the corpus and fundus. (C) The histological picture shows both a high grade component of large centroblast-like cells (right) and a low grade component of small centrocyte-like cells (lower left). (D) A follow up endoscopic view four months after the start of eradication therapy showing regression of the lymphomatous masses in the corpus and fundus.

patients with no regression or progression from 1 to 19 months (median 2.3) after the end of eradication. The strategies included gastrectomy (three patients) and oral monochemotherapy $^{24}$ (cyclophosphamide $100 \mathrm{mg} /$ day; four patients). Because two of the five patients with partial regression subsequently deteriorated, they were treated with alternative therapies (one with surgery and the other with oral monochemotherapy). The other three patients with partial regression have been under careful observation (follow up period 6-10 months after eradication). All patients were still alive at the time of this writing (survival time after eradication 69-1767 days; median 577).

The depth of tumour invasion determined by pretreatment EUS was as follows: all RLH cases and 28 of 41 MALT lymphomas (68\%; including all four cases showing a histological score of 4) were considered to be restricted to the mucosa without significant submucosal invasion (fig 1A); five cases of MALT lymphoma $(12 \%)$ were found to invade the deep portion of the submucosa (fig 1B); five MALT lymphomas $(12 \%)$ were considered to invade the muscularis propria (fig 1C); while the remaining three MALT lymphomas (7\%) were observed to reach the serosa (fig 1D). Perigastric lymphadenopathy (stage EII) was observed in five MALT lymphoma patients (fig
2). The depth of tumour invasion in these five patients was as follows: one lymphoma was restricted to the mucosa, two deeply invaded the submucosa, one involved the muscularis propria, and one reached the serosa. Accordingly, 30 patients with MALT lymphoma were classified as having stage $\mathrm{EI}_{1}$, six as stage $\mathrm{EI}_{2}$, and five as stage EII disease. ${ }^{712}$

Table 2 shows a comparison of the depth of invasion determined by EUS between the responding and non-responding cases with MALT lymphoma in relation to histological grade and clinical stage. The involvement in 26 of 27 cases with a low grade or focal high grade component which achieved complete regression was restricted to the mucosa. Two cases of high grade MALT lymphoma which unexpectedly showed complete regression had submucosal (fig 2) or muscular involvement. With regard to clinical staging, 25 of 30 cases in stage $\mathrm{EI}_{1}$, but only one of six cases in $\mathrm{EI}_{2}$, showed complete regression. However, three of the five lymphomas in stage EII unexpectedly achieved complete regression (fig 2); these three patients were followed up without any relapse for 211,658 , and 903 days after achieving complete regression.

Table 3 summarises the relation between complete regression of MALT lymphoma and pretreatment clinicopathological factors. 
Table 2 Comparison of depth of invasion determined by endoscopic ultrasonography between complete regression and partial or no regression of mucosa associated lymphoid tissue lymphoma cases in relation to histology and clinical stage

\begin{tabular}{|c|c|c|c|c|c|c|c|c|}
\hline & \multicolumn{4}{|c|}{ Complete regression } & \multicolumn{4}{|c|}{ Partial or no regression } \\
\hline & $m$ & $s m$ & $m p$ & serosa & $m$ & $s m$ & $m p$ & serosa \\
\hline \multicolumn{9}{|l|}{ Histological grade } \\
\hline Low $(n=31)$ & 23 & 0 & 1 & 0 & 2 & 2 & 1 & 2 \\
\hline Low with focal high $(n=5)$ & 3 & 0 & 0 & 0 & 0 & 1 & 1 & 0 \\
\hline High $(n=5)$ & 0 & 1 & 1 & 0 & 0 & 1 & 1 & 1 \\
\hline \multicolumn{9}{|l|}{ Clinical stage } \\
\hline $\mathrm{EI}_{1}(\mathrm{n}=30)$ & 25 & 0 & 0 & 0 & 2 & 3 & 0 & 0 \\
\hline $\mathrm{EI}_{2}(\mathrm{n}=6)$ & 0 & 0 & 1 & 0 & 0 & 0 & 3 & 2 \\
\hline EII $(n=5)$ & 1 & 1 & 1 & 0 & 0 & 1 & 0 & 1 \\
\hline
\end{tabular}

$\mathrm{m}$, mucosa; sm, submucosa; mp, muscularis propria.

†Ann-Arbor system modified by the German MALT Lymphoma Study Group.

Table 3 Relation between complete regression (CR) of mucosa associated lymphoid tissue lymphoma after eradication and pretreatment clinicopathological factors

\begin{tabular}{|c|c|c|c|c|}
\hline Factor & $\begin{array}{l}\text { No of } C R / \\
\text { all patients }\end{array}$ & $\begin{array}{l}\text { No of CR by } \\
12 \mathrm{Mt}\end{array}$ & $\begin{array}{l}\text { Probability of } C R \\
\text { at } 12 \mathrm{M \ddagger}\end{array}$ & $p$ Value * \\
\hline \multicolumn{5}{|c|}{ Depth of invasion by EUS } \\
\hline Mucosa & $26 / 28$ & $23 / 26$ & 0.85 & \multirow[t]{2}{*}{0.015} \\
\hline sm or beyond & $3 / 13$ & $3 / 12$ & 0.45 & \\
\hline \multicolumn{5}{|c|}{ Modified Ann Arbor stage } \\
\hline $\mathrm{EI}_{1}$ & $25 / 30$ & $23 / 27$ & 0.87 & \multirow[t]{2}{*}{0.0502} \\
\hline $\mathrm{EI}_{2} / \mathrm{EII}$ & $4 / 11$ & $3 / 11$ & 0.55 & \\
\hline \multicolumn{5}{|c|}{ Endoscopic appearance } \\
\hline SS type & $26 / 32$ & $23 / 29$ & 0.83 & \multirow[t]{2}{*}{0.085} \\
\hline Other types & $3 / 9$ & $3 / 9$ & 0.56 & \\
\hline \multicolumn{5}{|l|}{ H pylori density } \\
\hline Many $(3 / 2)$ & $23 / 30$ & $21 / 28$ & 0.86 & \multirow[t]{2}{*}{0.080} \\
\hline Few $(1 / 0)$ & $6 / 11$ & $5 / 10$ & 0.61 & \\
\hline \multicolumn{5}{|c|}{ High grade component } \\
\hline Yes & $5 / 10$ & $5 / 10$ & 1.00 & \multirow{2}{*}{0.908} \\
\hline No & $24 / 31$ & $21 / 28$ & 0.77 & \\
\hline \multicolumn{5}{|c|}{ Perigastric lymphadenopathy } \\
\hline Yes & $3 / 5$ & $2 / 5$ & 0.60 & \multirow[t]{2}{*}{0.736} \\
\hline No & $26 / 36$ & $24 / 33$ & 0.82 & \\
\hline \multicolumn{5}{|c|}{ Dominant site of lesion } \\
\hline Fundus/corpus & $23 / 34$ & $21 / 31$ & 0.79 & \multirow[t]{2}{*}{0.721} \\
\hline Antrum & $6 / 7$ & $5 / 7$ & 0.83 & \\
\hline
\end{tabular}

M, month; sm, submucosa; SS, superficial spreading.

† Subjects with partial regression who had been observed for less than 12 months were excluded. $\ddagger$ Kaplan-Meier analysis.

${ }^{\star}$ Log rank test.

qUpdated Sydney system.

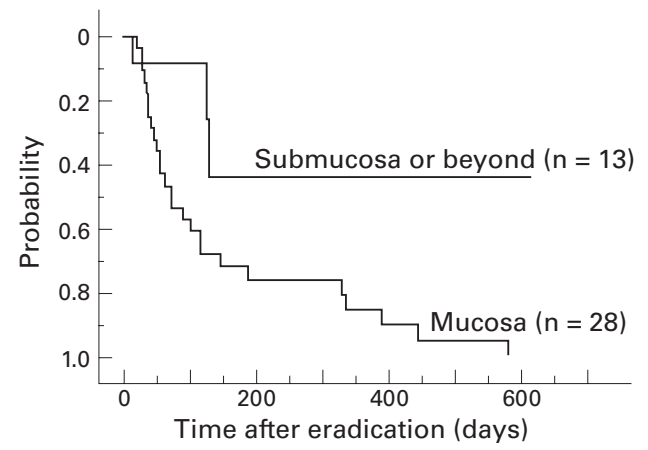

Figure 3 Kaplan-Meier analysis of the probability of having complete regression of gastric mucosa associated lymphoid tissue lymphoma by the indicated time in patients with tumours restricted to the mucosa and in those with tumours invading the deep portion of the submucosa or beyond (log rank test, $p<0.05$ ).

\section{Discussion}

$H$ pylori has been suggested to play a causative role in the development of gastric MALT lymphoma, ${ }^{3-5}$ and eradication of $H$ pylori is now considered to be the first choice of treatment for this type of lymphoma. ${ }^{6-12}$ Previous studies have described complete regression in approximately $60-90 \%$ of cases with low grade gastric MALT lymphoma after $H$ pylori eradication therapy, ${ }^{6-12}$ while lymphomas not responding to this treatment seemed to be frequently associated with high grade lesions. However, pretreatment differences between responding and non-responding lymphomas to this therapy have yet to be fully clarified as most studies, except for one report by Sackmann and colleagues, ${ }^{12}$ did not assess detailed pretreatment clinicopathological data such as endoscopic appearance, histology in the deep portion of the mucosa or submucosa, $H$ pylori density, or degree of depth of lymphomatous invasion to the gastric wall.

In the current study, we demonstrated that assessment of tumour invasion to the submucosa based on EUS rather than the modified Ann Arbor staging system ${ }^{12}$ appeared to be useful for predicting the response of gastric MALT lymphoma to $H$ pylori eradication (table 3, fig 3). In contrast with the study of Sackmann and colleagues, ${ }^{12}$ staging based on the modified Ann Arbor system did not correlate with the effect of eradication therapy, assessed using the Kaplan-Meier method. They reported that $86 \%$ of patients with stage $\mathrm{EI}_{1}$ and no patient with $\mathrm{EI}_{2}$ or EII disease achieved complete regression of the lymphoma. ${ }^{12}$ In our study, however, three of five patients with stage EII (perigastric lymphadenopathy) and one of six patients with $\mathrm{EI}_{2}$ (tumour invading the muscularis propria or serosa without lymphadenopathy) showed complete regression (table 2). In our three regressed lymphomas with stage EII, EUS after eradication therapy revealed all of the enlarged perigastric lymph nodes to have regressed together with the gastric lesions (fig 2, detailed data are not shown), as other investigators have also recently reported..$^{25}$ Although we cannot confirm whether or not lymphadenopathy in such patients is neoplastic or reactive, the results of the present study suggest that clinical 
stage EII does not seem to be a contraindication for eradication therapy.

Conversely, only one of five (20\%) patients with lymphoma invaded to the deep portion of the submucosa and 26 of 28 (93\%) tumours restricted to the mucosa showed complete regression in our study. Therefore, we would like to stress that among $\mathrm{EI}_{1}$ cases, lymphomas restricted to the mucosa without significant submucosal invasion should be distinguished from those deeply invading the submucosa by EUS.

Before eradication therapy, we recognised a high grade component in 10 patients by conventional biopsy in five and endoscopic mucosal resection in five..$^{13}$ Interestingly, five of 10 lymphomas with high grade lesions also showed complete regression in our series (table 2, fig 2), and the presence or absence of a high grade component did not influence the effect of $H$ pylori eradication therapy (table 3). Although a previous large series from Germany described most of the non-responding lymphomas after $H$ pylori eradication as high grade tumours, ${ }^{711}$ recent reports have also described cases in which high grade large B cell lymphomas regressed after eradication therapy. ${ }^{26} 27$ Among the 10 cases with a high grade component in our study, three of five lymphomas with complete regression were restricted to the mucosa, while all five tumours with partial or no regression invaded the deep portion of the submucosa or beyond (table 2). Thus we speculate that high grade MALT lymphomas may also respond to $H$ pylori eradication when the lesion is restricted to the mucosa.

Other clinicopathological factors listed in table 3 also seemed to show a possible association with regression of the lymphoma after $H$ pylori eradication but the differences were not statistically significant. In our study, endoscopic appearance alone failed to predict the subsequent response to eradication. This seems to be due in part to the discrepancy between EUS findings and endoscopic appearance, because four of the 32 lymphomas regarded as superficial spreading type invaded the deep portion of the submucosa or beyond. While a large number of subjects are warranted to draw definite conclusions, EUS does not seem to be complementary but rather it is an independent procedure for predicting the therapeutic efficacy of eradication in MALT lymphoma.

The rate of complete regression of MALT lymphoma $(71 \%)$, which was comparable with previously reported data, ${ }^{6-12}$ was significantly lower than that of RLH (100\%) in our study (table 1). From this point of view, we consider that RLH should be strictly distinguished from MALT lymphoma. However, the differential diagnosis between RLH and early gastric MALT lymphoma is difficult. ${ }^{13}$ These two diseases are indistinguishable either by endoscopy or EUS when the lesion is restricted to the mucosa. When a conventional biopsy is insufficient to make a final diagnosis, a detailed histological assessment using the endoscopic mucosal resection technique ${ }^{13}$ or molecular examinations by polymerase chain reaction ${ }^{14}$ should be considered. In the current study, we included four cases with a Wotherspoon's histological score of 4 in the MALT lymphoma group, as previously described by Wotherspoon and colleagues ${ }^{6}$ and Savio and colleagues; Bayerdörffer and colleagues ${ }^{7}$ included only cases with score of 5 . It is still controversial as to whether lesions with a score of 4 should be categorised as MALT lymphoma or RLH. However, even when we excluded the four patients with a score of 4 from the analysis, the results summarised in table 3 were not affected (data are not shown).

The precise mechanisms behind regression of lymphoma after $H$ pylori eradication are still unclear although several experimental studies have suggested some hypotheses. ${ }^{28-30}$ Recently, genetic abnormalities which may be specific for MALT lymphoma have been demonstrated. ${ }^{31-33}$ Chong and colleagues ${ }^{32}$ reported that genetic instability may be an important mechanism for the development and progression of gastric lymphoma, and they described the possible usefulness of screening four markers for microsatellite instability to predict the effect of $H$ pylori eradication therapy. As we have shown in the current study, almost all cases with gastric MALT lymphoma restricted to the mucosa were considered to regress after eradication therapy, but in tumours invading the submucosa deeply or beyond, differences between the cases which responded to this therapy and those who did not were still unclear. Further investigations, including molecular analyses, are essential to precisely predict the effect of eradication therapy on gastric MALT lymphoma.

In addition, it is not certain if complete regression of gastric MALT lymphoma continues for a prolonged period after eradication. In the current study, all 29 patients who had achieved complete regression did not relapse during the subsequent period (median follow up period 20.5 months in all patients; one year or more in 22 patients; two years or more in 12 patients). In a large study by Neubauer and colleagues, ${ }^{10}$ however, five of 40 patients with complete regression of gastric MALT lymphoma later manifested local relapses or developed nasal high grade lymphoma during a period ranging from 128 to 481 days after complete regression. Thus complete regression of gastric MALT lymphoma does not necessarily mean "cure" of the disease. ${ }^{1011}$ Longer follow up studies in a larger number of patients are needed to clarify if $\mathrm{H}$ pylori eradication may indeed cure this disease.

In conclusion, EUS is valuable for predicting the efficacy of $H$ pylori eradication for gastric MALT lymphoma. While the number of subjects in this study was small, the presence or absence of deep submucosal invasion as assessed by EUS was the most critical factor for pretreatment assessment. We therefore believe that EUS should be included as part of the staging procedures for the diagnosis and treatment of gastric MALT lymphoma. The authors thank Professor Tsuneyoshi Yao, Dr Mitsuo
Okada, Dr Akinori Iwashita, Dr Koh-ichi Ohshima (Fukuoka University), Dr Tadahiko Fuchigami, and Dr Yuji Sakai (Matsuyama Red Cross Hospital) for their kind cooperation; (Matsuyama Red Cross Hospital) for their
and Brian Quinn for editing the manuscript. 
1 Freeman C, Berg JW, Cutler SJ. Occurrence and prognosis of extranodal lymphomas. Cancer 1972;29:252-60.

2 Nakamura $S$, Akazawa $K$, Yao T, et al. Primary gastric lymphoma: a clinicopathologic study of 233 cases with special reference to evaluation with the MIB-1 index. Cancer 1995;76:1313-24.

3 Wotherspoon AC, Ortiz-Hidalgo C, Falzon MR, et al. Helicobacter pylori-associated gastritis and primary B-cell gastric lymphoma. Lancet 1991;338:1175-6.

4 Parsonnet J, Hansen S, Rodriguez L, et al. Helicobacter pylori infection and gastric lymphoma. $N$ Engl F Med 1994;330: 1267-71.

5 Nakamura S, Yao T, Aoyagi K, et al. Helicobacter pylori and primary gastric lymphoma: a histopathologic and immunohistochemical analysis of 237 patients. Cancer 1997;79:311.

6 Wotherspoon AC, Doglioni C, Diss TC, et al. Regression of primary low-grade B-cell gastric lymphoma of mucosaassociated lymphoid tissue type after eradication of Helicobacter pylori. Lancet 1993;342:575-7.

7 Bayerdörffer E, Neubauer A, Rudolph B, et al. Regression of primary gastric lymphoma of mucosa-associated lymphoid tissue type after cure of Helicobacter pylori infection. Lancet 5: $1591-4$

8 Roggero E, Zucca E, Pinotti G, et al. Eradication of Helicobacter pylori infection in primary low-grade gastric lymphoma of mucosa-associated lymphoid tissue. Ann Intern Med 1995;122:767-9.

9 Savio A, Franzin G, Wotherspoon AC, et al. Diagnosis and posttreatment follow-up of Helicobacter pylori-positive gastric lymphoma of mucosa-associated lymphoid tissue: histology, polymerase chain reaction, or both? Blood 1996 , 87:1255-60.

10 Neubauer A, Thiede C, Morgner A, et al. Cure of Helicobacter pylori infection and duration of remission of low-grade gastric mucosa-associated lymphoid tissue lymphoma. 尹 Natl Cancer Inst 1997;89:1350-5.

11 Thiede C, Morgner A, Alpen B, et al. What role does Helicobacter pylori eradication play in gastric MALT and gastric bacter pylori eradication play in gastric MALT and gastric
MALT lymphoma? Gastroenterology 1997;113(suppl): S61-4.

12 Sackmann M, Morgner A, Rudolph B, et al. Regression of gastric MALT lymphoma after eradication of Helicobacter pylori is predicted by endosonographic staging. Gastroenter ology 1997; 113:1087-90.

13 Suekane H, Iida M, Kuwano Y, et al. Diagnosis of primary early gastric lymphoma: usefulness of endoscopic mucosal resection for histologic evaluation. Cancer 1993;71:120713.

14 Nakamura S, Aoyagi K, Furuse M, et al. B-cell monoclonality precedes the development of gastric MALT lymphoma in Helicobacter pylori-associated chronic gastritis. Am $\mathcal{F}$ Pathol 1998;152:1271-9.

15 Chan JKC, Ng CS, Isaacson PG. Relationship between high-grade lymphoma and low-grade B-cell mucosaassociated lymphoid tissue lymphoma (MALToma) of the stomach. Am f Pathol 1990;136:1153-64.

16 de Jong $\mathrm{D}$, Boot $\mathrm{H}$, van Heerde $\mathrm{P}$, et al. Histological grading in gastric lymphoma: pretreatment criteria and clinical relin gastric lymphoma: pretreatment criteria and

17 Dixon MF, Genta RM, Yardley JH, et al. Classification and grading of gastritis: the updated Sydney system. Am $\mathcal{F}$ Surg Pathol 1996;20:1161-81.
18 Carbone PP, Kaplan HS, Musshoff K, et al. Report of the committee on Hodgkin's disease staging procedures. Cancer Res 1971;31:1860-1.

19 Musshoff K. Klinische Stadieneinteilung der nichtHodgkin-Lymphome. Strahlentherapie 1977;153:218-21.

20 Suekane H, Iida M, Yao T, et al. Endoscopic ultrasonography in primary gastric lymphoma: correlation with endoscopic and histologic findings. Gastrointest Endosc 1993;39:139-45.

21 Pavlick AC, Gerdes H, Portlock CS. Endoscopic ultrasound in the evaluation of gastric small lymphocytic mucosaassociated lymphoid tumors. F Clin Oncol 1997;15:1761-6.

22 Lévy M, Hammel P, Lamarque D, et al. Endoscopic ultrasonography for the initial staging and follow-up in patients with low-grade gastric lymphoma of mucosaassociated lymphoid tissue treated medically. Gastrointest Endosc 1997;46:328-33.

23 Radaszkiewicz T, Dragosics B, Bauer P. Gastrointestinal malignant lymphomas of the mucosa-associated lymphoid tissue: factors relevant to prognosis. Gastroenterology 1992; 102:1628-38.

24 Blazquez M, Haioun C, Chaumette M-T, et al. Low grade B cell mucosa associated lymphoid tissue lymphoma of the stomach: clinical and endoscopic features, treatment, and outcome. Gut 1992;33:1621-5.

25 Shirai T, Takagi A. Role of H. pylori eradication in gastric MALT lymphoma with regional lymphadenopathy. Dig Endosc 1998;10:97.

26 Rudolph B, Bayerdörffer E, Ritter M, et al. Is the polymerase chain reaction or cure of Helicobacter pylori infection of help in the differential diagnosis of early gastric mucosaassociated lymphatic tissue lymphoma? f Clin Oncol 1997; 15:1104-9.

27 Seymour JF, Anderson RP, Bhathal PS. Regression of gastric lymphoma with therapy for Helicobacter pylori infection. Ann Intern Med 1997;127:247.

28 Hussell T, Isaacson PG, Crabtree JE, et al. The response of cells from low-grade B-cell gastric lymphomas of mucosaassociated lymphoid tissue to Helicobacter pylori. Lancet 1993;342:571-4.

29 Hussell T, Isaacson PG, Crabtree JE, et al. Helicobacter pylori-specific tumour-infiltrating $\mathrm{T}$ cells provide contact dependent help for the growth of malignant B cells in lowgrade gastric lymphoma of mucosa-associated lymphoid tissue. I Pathol 1996;1 178:122-7.

30 Enno A, O'Rourke J, Braye S, et al. Antigen-dependent progression of mucosa-associated lymphoid tissue (MALT)type lymphoma in the stomach: Effects of antimicrobial therapy on gastric MALT lymphoma in mice. Am $\mathcal{F}$ Pathol 1998;152:1625-32.

31 Wotherspoon AC, Finn TM, Isaacson PG. Trisomy 3 in ow-grade B-cell lymphomas of mucosa-associated lymphoid tissue. Blood 1995;85:2000-4.

32 Chong J-M, Fukayama M, Hayashi Y, et al. Microsatellite instability and loss of heterozygosity in gastric lymphoma. Lab Invest 1997;77:639-45.

33 Ott G, Katzenberger T, Greiner A, et al. The $\mathrm{t}(11 ; 18)(\mathrm{q} 21$; q21) chromosome translocation is a frequent and specific aberration in low-grade but not high-grade malignant nonHodgkin's lymphomas of the mucosa-associated lymphoid tissue (MALT-) type. Cancer Res 1997;57:3944-8. 